\title{
El Parlamento Abierto como mecanismo de rendición ético-social de cuentas en la discusión sobre la seguridad en México
}

\author{
Open Parliament as a mechanism for ethical-social \\ accountability in the discussion of security in Mexico \\ Roberto Ignacio Alonso Muñoz \\ Universidad Iberoamericana Puebla \\ roberto.alonso@iberopuebla.mx
}

doi: http://dx.doi.org/10.18543/djhr.1792

Fecha de recepción: 11.12.2019

Fecha de aceptación: 20.04.2020

Cómo citar/Citation: Alonso, Roberto I. 2020. «El Parlamento Abierto como mecanismo de rendición ético-social de cuentas en la discusión sobre la seguridad en México». Deusto Journal of Human Rights, n. 5: 125-154. doi: http://dx.doi.org/10.18543/djhr.1792

Sumario: Introducción. 1. La crisis de representatividad y confianza en México. 2. Parlamento Abierto y participación ciudadana. 2.1. El Parlamento Abierto visto desde el gobierno abierto. 2.2. Más allá de transparencia legislativa. 2.3. Participación ciudadana en el ámbito parlamentario. 3. Hacia una rendición ético-social de cuentas. 3.1. Rendición de cuentas, un proceso relacional. 3.2. La rendición social de cuentas. 3.3. Rendir cuentas desde una perspectiva ética. 4. El futuro de la seguridad en México en Parlamento Abierto. 4.1. La apuesta por la militarización. 4.2. Movilización social en torno a la Ley de Seguridad Interior. 4.3. Participación ciudadana y audiencias públicas: la Guardia Nacional. 4.4. Responsabilidad, representación y deliberación en la discusión de la LSI y la creación de la GN. Conclusiones. Bibliografía.

Resumen: La idea de apertura que acompaña los propósitos del gobierno abierto alcanza otros espacios institucionales como el parlamento. Allí, en medio de una crisis de representatividad por los bajos niveles de confianza que genera esta institución, la noción de Parlamento Abierto se enfrenta al desafío de dar paso a esquemas deliberativos que permitan la cocreación con la sociedad. El Parlamento Abierto resulta un mecanismo de rendición social de cuentas al vehiculizar la incidencia de actores sociales. Pero por sí sola, la movilización social no garantiza desenlaces en los que se privilegie el bien común, siendo necesario un examen ético. Este artículo se pregunta bajo qué condiciones el Parlamento Abierto resulta un mecanismo efectivo de rendición 
ético-social de cuentas, analizando el papel del colectivo Seguridad Sin Guerra en la discusión sobre la seguridad en México, en cuyo caso pueden observarse consideraciones de sustrato ético como la responsabilidad, la representación y la deliberación.

Palabras clave: Parlamento Abierto, rendición social de cuentas, participación ciudadana, democracia deliberativa, ética.

Abstract: The idea of openness, which invariably accompanies the purposes of an open government, reaches other institutional spaces such as parliament. In the midst of a crisis of representation due to the low levels of trust generated by this institution, the notion of an Open Parliament visualizes the challenge of giving way to deliberative schemes that allow co-creation with society. An Open Parliament is a mechanism of social accountability by bolstering the incidence of social actors. But by itself, social mobilization does not guarantee outcomes in which the common good is prioritized, since it also requires an ethical examination. This paper asks under what conditions an Open Parliament would be an effective mechanism for ethicalsocial accountability. This is done by analyzing the role played by the group Seguridad Sin Guerra in the discussion on security in Mexico, in which ethical issues such as responsability, representation and deliberation can be observed.

Key words: Open Parliament, social accountability, citizen participation, deliberative democracy, ethics. 


\section{Introducción}

La democracia mexicana vive una crisis de representatividad que, no siendo exclusiva en la región, presenta síntomas evidentes. El contexto es de mayor calado y tiene como telón de fondo un proceso de globalización neoliberal cuyo correlato funcional es el de una democracia de baja intensidad. La representación política fundada en los procedimientos electorales ha sido un instrumento eficaz para incorporar la voz de la ciudadanía, pero la crisis de representatividad hace necesario explorar nuevas formas para recuperar la confianza en el poder público. Si en la democracia representativa la legitimidad descansa en la delegación del poder, en la democracia participativa lo hace en la generación de consensos en las decisiones (Aguilar 2014), a través de una deliberación más abierta e inclusiva.

Por ello la pertinencia de ahondar en la participación ciudadana y de aspirar a una democracia de mayor intensidad. $Y$ en este horizonte se presenta el Parlamento Abierto como una forma de innovación política que favorece una interacción entre el parlamento y la sociedad caracterizada por la transparencia, la participación, la colaboración y la rendición de cuentas. Una innovación que, además, puede ser útil para blindar a la institución parlamentaria de la influencia desmedida de fuerzas contrarias a la construcción de sociedades justas, de ahí que pueda ser pensada en términos éticos.

La pregunta que guía el presente artículo es bajo qué condiciones el Parlamento Abierto resulta un mecanismo efectivo de rendición éticosocial de cuentas, en el marco de la crisis de representatividad que atraviesa México. Para responder esta pregunta se recorre la siguiente ruta: primero se da cuenta de algunos de los rasgos de la crisis de representatividad en este país; después se presenta el Parlamento Abierto como aplicación en la institución legislativa de los principios del gobierno abierto; más adelante se propone un marco analítico con variantes éticas que reposa en la rendición social de cuentas; enseguida se analiza el papel del colectivo Seguridad Sin Guerra ${ }^{1}$ en la discusión legislativa acontecida en México en torno al combate al narcotráfico y al crimen organizado entre 2017 y 2019; y finalmente se hace un

1 Este colectivo se conformó a finales de 2016 con la articulación de organizaciones civiles, especialistas, académicos y ciudadanos preocupados por la aprobación de una Ley de Seguridad Interior que, a su juicio, buscó perpetuar un modelo de seguridad fallido, basado en la militarización. Entre 2017 y 2019 se convirtió en un referente en la discusión sobre la seguridad en México, tanto por su crítica como por sus propuestas encaminadas a construir un nuevo paradigma de seguridad en el país. 
balance del Parlamento Abierto para avanzar hacia democracias de alta intensidad.

El análisis empírico que plantea este trabajo está basado en el análisis documental, recurriendo fundamentalmente a los informes y posicionamientos que hicieron el colectivo Seguridad Sin Guerra y organizaciones que lo integran, material periodístico y las iniciativas legislativas en discusión: la Ley de Seguridad Interior y las reformas constitucionales para crear la Guardia Nacional. La elección de este caso obedeció a que la problemática alrededor de la seguridad en México se ha agudizado en la última década, con un saldo preliminar de 250.000 homicidios, más de 60.000 desaparecidos, más de 3.500 fosas clandestinas y una crisis generalizada de derechos humanos.

\section{La crisis de representatividad y confianza en México}

Los resultados del Informe de la Corporación Latinobarómetro (2018) muestran indicadores preocupantes. Ya el informe de 2017 diagnosticaba una democracia diabética con un paulatino deterioro en ellos. Según el Informe 2018, ningún indicador tuvo una evolución positiva, mientras que la caída de varios llegó a mínimos históricos, siendo la desconfianza ciudadana en las instituciones uno de los principales problemas de la democracia latinoamericana.

El informe revela una caída de siete años consecutivos en el apoyo a la democracia, no aislada de una ausencia en la percepción de progreso en la región ${ }^{2}$ y de un descontento de la mitad de la población por problemas económicos ${ }^{3}$. La democracia está en serios problemas. La apoya sólo un $48 \%$ de los latinoamericanos, aumentando en correspondencia el porcentaje de ciudadanos desencantados que se declaran indiferentes al tipo de régimen. Este último indicador pasó del $16 \%$ en 2010 al $28 \%$ en 2018 , el mayor porcentaje en 23 años de medición. En México, el apoyo actual a la democracia es del 38\%, mismo porcentaje que el de los mexicanos indiferentes al tipo de régimen.

2 Con excepción de Bolivia, donde un 44\% percibe progreso, en el resto de los países la percepción de progreso es del 33\% o menos. En el caso de México, sólo el $14 \%$ de la población lo percibe.

3 En México, un 54\% de la población aprecia que la situación económica del país es mala, en contraste con un $9 \%$ que la considera buena. La gran mayoría de los mexicanos (88\%) cree que se gobierna para beneficio de unos cuantos grupos, y apenas el $12 \%$ estima que la distribución de la riqueza es justa. 
Sólo un $5 \%$ de los latinoamericanos considera que hay plena democracia, un $23 \%$ afirma que ésta presenta pequeños problemas, un $45 \%$ cree que hay grandes problemas y un $14 \%$ opina que no hay democracia. En México, el $67 \%$ estima que se trata de una democracia con problemas. El porcentaje latinoamericano de insatisfechos con la democracia es del $71 \%$, seis puntos por arriba del año anterior. En México, apenas el $16 \%$ de la población está satisfecha con la democracia.

En medio de este panorama, la Corporación Latinobarómetro (2018) presenta los niveles de confianza hacia ocho instituciones. En el gráfico 1 se presenta una comparación entre el promedio latinoamericano y la confianza existente en México.

\section{Gráfico 1}

\section{Comparativo de los niveles de confianza institucional. México/América Latina}

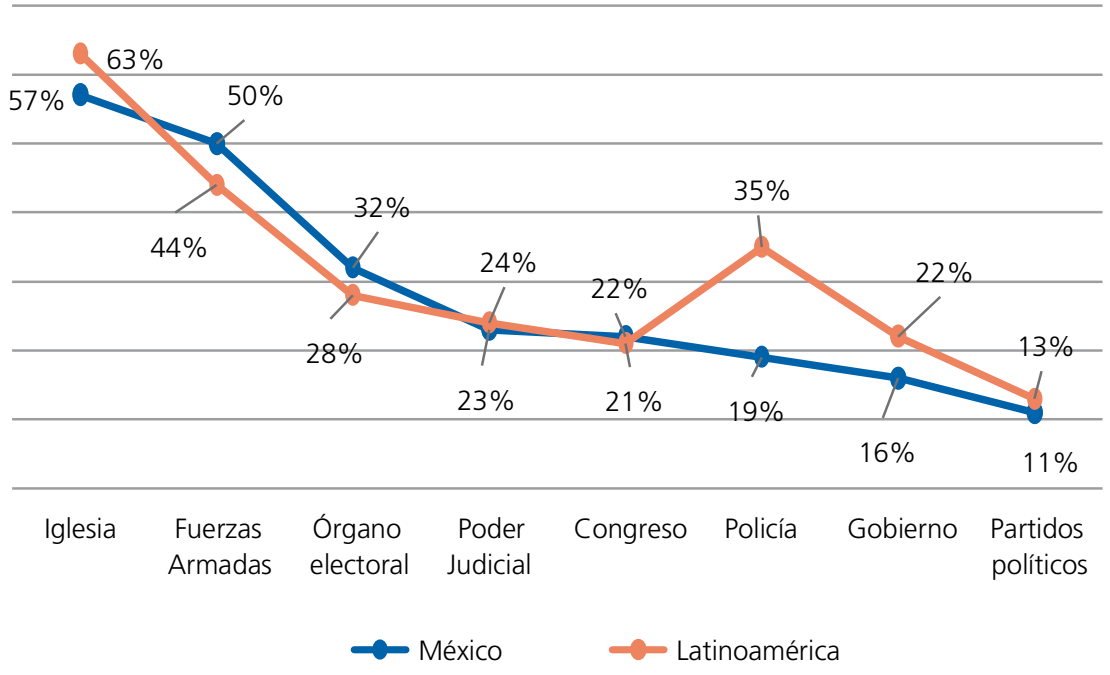

Fuente: Elaboración propia con base en Corporación Latinobarómetro (2018).

En sintonía, la encuesta realizada por Mitofsky (2019) en México, indica que la policía, los senadores, los sindicatos, los partidos políticos y los diputados son las instituciones con los más bajos niveles de confianza. 
Gráfico 2

Evolución de la baja confianza institucional en México. 2013-2018

\begin{tabular}{|c|c|c|c|c|c|c|c|c|}
\hline \multirow{7}{*}{ 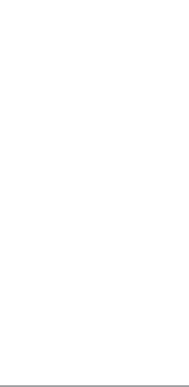 } & \multicolumn{8}{|l|}{8} \\
\hline & \\
\hline & 4 & & & & & & & \\
\hline & 3 & & & & & & & \\
\hline & 2 & & & & & & & \\
\hline & 1 & & & & & & & \\
\hline & 0 & 2013 & 2014 & 2015 & 2016 & 2017 & 2018 & 2019 \\
\hline Presidencia & & 6,2 & 6,1 & 5,7 & 5,1 & 4,8 & 5,1 & 7 \\
\hline Policía & & 5,8 & 5,5 & 5,3 & 5 & 4,9 & 5,5 & 5,7 \\
\hline Sindicatos & & 5,7 & 5,5 & 5,4 & 4,9 & 5 & 5,4 & 5,5 \\
\hline Senadores & & 5,7 & 5,7 & 5,3 & 5,2 & 4,8 & 5,3 & 5,5 \\
\hline Partidos polític & & 5,2 & 5,3 & 4,9 & 4,8 & 4,4 & 5,1 & 5,4 \\
\hline Diputados & & 5,6 & 5,7 & 5,2 & 5 & 4,6 & 5,1 & 5,3 \\
\hline
\end{tabular}

Fuente: Elaboración propia con base en Mitofsky (2019)

México enfrenta un gran reto ante la nueva etapa política que inaugura el primer gobierno de izquierda en la historia moderna del país. Es en este momento histórico en el que se abre una oportunidad para profundizar en nuevos mecanismos deliberativos.

\section{Parlamento Abierto y participación ciudadana}

El concepto de Parlamento Abierto está en discusión. Algo similar ocurre con el de gobierno abierto; no obstante, este último ha experimentado un importante desarrollo empírico y teórico en los últimos años, particularmente desde la creación de la Alianza para el Gobierno Abierto (AGA).

Por lo que hace al gobierno abierto es posible identificar un parteaguas a partir de la publicación de los memorandos Transparency and Open Government y Open Government Directive, el primero firmado por Barack Obama al iniciar su administración y el segundo con la rúbrica del entonces director de la Oficina de Administración y Presupuesto de los Estados Unidos. Obama se comprometió a impulsar un nivel de apertura gubernamental sin precedentes a partir de tres principios: 
transparencia, participación y colaboración, siendo así como se dinamizó, en palabras de Ramírez-Alujas (2010), una «vieja nueva idea».

\subsection{El Parlamento Abierto visto desde el gobierno abierto}

El gobierno abierto emerge como una propuesta ante los retos que enfrentan las democracias a nivel global, entre ellos su limitada capacidad de respuesta y la búsqueda de legitimidad en el ejercicio del poder. Pero resulta importante puntualizar que la conceptualización de apertura no es unívoca. El hecho de que la idea contemporánea de gobierno abierto esté fundada en cuatro líneas genéricas ha derivado en una diversidad de iniciativas a nivel internacional, nacional y local. En cualquier caso, es posible coincidir en algunos elementos centrales que permiten formular definiciones aceptadas, a saber: una forma novedosa de entender y abordar los procesos de gobierno, el reconocimiento de que la esfera gubernamental no es la única legítima y capaz para dar respuesta a las necesidades sociales y, en este sentido, la relevancia de la participación ciudadana en las soluciones a los problemas públicos.

González (2016) distingue al gobierno abierto del enfoque de gobierno electrónico y de los esfuerzos de transparencia gubernamental. Con una fuerte impronta de los avances tecnológicos, el gobierno electrónico comparte con el gobierno abierto «la aspiración de mejorar el desempeño del gobierno y la calidad de la interacción entre éste y los ciudadanos» (González 2016, 14). Sin embargo, el primero consiste básicamente en el uso de las tecnologías de información en el sector gubernamental para mejorar su eficiencia, independientemente de principios normativos como la participación, la colaboración y la rendición de cuentas.

Por lo que toca a la transparencia, la confusión se suele presentar a la hora de reducir el gobierno abierto a una de sus dimensiones. En efecto, en la transparencia el gobierno abierto encuentra una de sus columnas y, por tanto, una de sus cruzadas, entendiéndola como un asunto de carácter proactivo. Pero el gobierno abierto supera a la transparencia al incluir, adicionalmente, participación ciudadana, rendición de cuentas y un modelo más horizontal de relacionamiento entre el gobierno y la sociedad.

Cruz-Rubio (2015) agrupa distintas definiciones de gobierno abierto en dos grupos. Por un lado, como nuevo paradigma de gobernanza, por su énfasis relacional entre gobierno y sociedad; y, por otro lado, como estrategia de gobierno para alcanzar sus propios fines. La AGA lo entiende como: 
un nuevo modelo de gestión en el que ciudadanos y autoridades colaboran para producir políticas públicas y acciones encaminadas a construir soluciones colaborativas a problemas públicos, donde la participación y la transparencia son considerados elementos mínimos que sirven para dar atención a las demandas sociales, pero también promover ambientes sólidos de rendición de cuentas, innovación social y apertura institucional que son capaces de generar valor público (Secretariado Técnico Tripartita 2016,4).

Esta aproximación da lugar al abordaje del Parlamento Abierto. Considerando el potencial del concepto para la construcción de democracias de alta intensidad, este trabajo opta por la perspectiva que lo sitúa desde los principios nucleares de la nueva idea de gobierno abierto: transparencia, participación, colaboración y rendición de cuentas. En esta línea, ParlAmericas $(2018,3)^{4}$ concibe al Parlamento Abierto como:

una nueva forma de interacción entre la ciudadanía y las legislaturas que promueve la apertura y transparencia parlamentaria para garantizar el acceso a la información pública, la rendición de cuentas, la participación ciudadana y altos estándares éticos.

Esta manera de entender al Parlamento Abierto recupera los objetivos medulares de la AGA, asociándolo con aquellos procesos tendientes a impulsar nuevos paradigmas de relación entre los poderes instituidos y la sociedad.

Por ello se dice que el Parlamento Abierto puede ser comprendido al menos desde tres vertientes: la discusión sobre la representación democrática, la incorporación de la tecnología a esta institución y como correlato del gobierno abierto (Puente y Luna 2018). Para los fines del presente artículo se hace hincapié en la tercera, es decir, la relación que existe entre el Parlamento Abierto y los principios seminales de transparencia, participación y colaboración, añadiendo el de rendición de cuentas 5 .

4 ParlAmericas es una red parlamentaria independiente compuesta por las legislaturas nacionales de 35 países del continente. Entre sus finalidades se encuentra la de impulsar parlamentos abiertos.

5 La AGA retoma la rendición de cuentas y el acceso a las nuevas tecnologías en su concepción nuclear, por ello y en función de los alcances de este trabajo, se retoma el principio de rendición de cuentas, no así el relativo a las nuevas tecnologías que se asumen como una narrativa adicional. 


\subsection{Más allá de transparencia legislativa}

De manera previa a la evolución del concepto de apertura que trajo consigo la AGA, la Unión Interparlamentaria sentó un precedente significativo al publicar en 2006 una guía de buenas prácticas parlamentarias en el siglo XXI. En un contexto global de creciente pérdida de legitimidad de los parlamentos, esta organización planteó la década pasada cinco características que debía reunir un parlamento democrático: representatividad, apertura y transparencia, accesibilidad, eficacia y rendición de cuentas.

Respecto a la segunda, la guía vincula la apertura y la transparencia parlamentarias asentando la importancia de que las deliberaciones de esta institución estén abiertas al público con ayuda de los medios de comunicación y las libertades de información y expresión (Beetham 2006). No obstante, este nivel de apertura queda muy corto si se le contrasta con el trasfondo que subyace en la noción de gobierno abierto.

El Parlamento Abierto puede ser confundido con la transparencia parlamentaria que, aunque la incluye, no lo agota. Con todo, la participación ciudadana, la colaboración y la rendición de cuentas no son posibles sin información, de ahí que convenga visualizar la transparencia legislativa como el piso mínimo de un Parlamento Abierto.

Un documento que recoge las expectativas sociales en esta dirección de alrededor de 150 organizaciones de 80 países sobre los parlamentos nacionales y subnacionales es la Declaración sobre la Transparencia Parlamentaria (Opening Parliament 2012). En el caso de México, esta declaración fue tomada en cuenta por el segmento de organizaciones sociales de la Alianza para el Parlamento Abierto ${ }^{6}$ a fin de presentar diagnósticos sobre el estado del Parlamento Abierto en el país. El primero se realizó en 2015 y el segundo en 2017.

A nivel regional cabe resaltar el Î́ndice Latinoamericano de Transparencia Legislativa, elaborado por la Red Latinoamericana de Transparencia Legislativa, con cuatro ediciones hasta 2018. El objetivo de este índice es aportar una medición acerca de la existencia de políticas y mecanismos de transparencia y participación ciudadana en los parlamentos de Latinoamérica. La participación ciudadana, sin embargo, se limita a la cercanía con ella sin concebir el trabajo conjunto.

6 Es un espacio de encuentro de organizaciones de la sociedad civil, instituciones legislativas y el órgano garante de la transparencia a nivel nacional. 
Como se infiere, estos ejercicios responden fundamentalmente a la dimensión de apertura parlamentaria o transparencia legislativa. Examinan con mayor profundidad la dimensión de apertura, no la dimensión relacional. La primera implica «datos disponibles o accesibles para cualquier persona u organización sin ninguna restricción» a partir de un compromiso activo con la información pública. La segunda dimensión «se da en el momento en que los individuos son parte integrante, con su expertise, junto con el gobierno en el proceso de hechura de las decisiones para generar soluciones que luego serán implementadas» (Mariñez 2016, 10-11), abriendo paso a la idea de cocreación.

Comprender el Parlamento Abierto como resultado de la aplicación de los principios de transparencia, participación, colaboración y rendición de cuentas es oportuno en un marco global. Desafiados los Estados-nación en el ecosistema global, una mirada a esta misma escala como la de la AGA supone una ventaja en la alineación de las transformaciones institucionales necesarias para enfrentar los retos que le impone el proceso de globalización dominante a las instituciones democráticas.

Al mundo globalizado, no se le corresponden instituciones políticas que tengan la misma escala que los problemas que deben responder y resolver [...] Mientras llegan reformas que hagan posibles instituciones democráticas más globales, los parlamentos exploran y ensayan prácticas y procedimientos que les permitan reconstruir los puentes de confianza con la ciudadanía (Gutiérrez-Rubí 2014, 366-367).

La propia AGA, dentro de la cual existe un grupo de trabajo sobre apertura legislativa, ha presentado una guía para orientar las políticas de gobierno abierto en temas focalizados, entre ellos la institución parlamentaria. Estos esfuerzos dan cuenta del interés de trascender la sola transparencia legislativa.

\subsection{Participación ciudadana en el ámbito parlamentario}

Dado que en la siguiente sección se abordará la rendición de cuentas en su veta social, conviene ahora analizar el componente de participación ciudadana, que de suyo es el que interpela al entramado institucional desde la concepción de apertura esgrimida.

«El Parlamento Abierto no debe contentarse con enseñarse a la sociedad, abrir sus puertas implica también involucrar a los ciudadanos en torno a temas de interés» (Rubio 2014, 411). 
En este entendido, señala el mismo autor, los parlamentos han de buscar las fórmulas para adaptarse a las demandas de participación, toda vez que «para que una democracia florezca, la ciudadanía debe jugar un papel relevante en la vida pública [...] asumiendo como propia la responsabilidad del bienestar de la propia comunidad» (Rubio 2014, 412).

Los estándares de participación y cocreación de la AGA comprenden la participación ciudadana como un elemento esencial para implementar reformas duraderas de gobierno abierto. De esta manera, la AGA retoma algunos principios reconocidos a nivel global para una participación ciudadana efectiva, destacando que esta, entre otros rasgos, se basa en la convicción de que aquellos que son afectados por una decisión tienen derecho a participar en el proceso de toma de la misma y ofrece a los participantes la información que requieren para poder participar de forma significativa.

Para el caso del Parlamento Abierto, la participación ciudadana se entiende como el «involucramiento activo de las y los ciudadanos en los procesos de toma de decisiones legislativas que les permiten contribuir en aquellas decisiones que pueden tener un impacto en su vida» (ParlAmericas 2017, 10), coadyuvando a una toma de decisiones más inclusiva y representativa, al aumento de la confianza ciudadana, al fortalecimiento de la legitimidad y a que haya parlamentos más transparentes y que rindan cuentas.

En el proceso legislativo la participación ciudadana puede darse en sus distintas etapas a través de acciones como la identificación de problemas que requieren soluciones legislativas, la propuesta de dichas soluciones, la contribución de ciudadanos en el texto legislativo, la implementación y la evaluación del producto legislativo (ParlAmericas 2017). El proceso de elaboración o reforma de una ley, no obstante, es apenas una de las funciones de un parlamento, a la que se suman las administrativas, de control, presupuestarias, jurisdiccionales y de diplomacia parlamentaria (Puente y Luna 2018).

Frente a las posiciones que asumen la existencia de un monopolio del poder en las figuras de representación política:

se encuentran los que entienden que poner en marcha canales de participación de los ciudadanos en la vida parlamentaria supondrá un refuerzo en la legitimidad de las decisiones que se toman, además de enriquecer los debates con la integración de la opinión de las personas que están más inmediatamente afectadas (Aranda 2017, 37).

En México, una buena práctica de participación ciudadana desde los principios de Parlamento Abierto fue el acompañamiento 
técnico ciudadano que se brindó en 2014 para la designación de los comisionados del órgano garante de la transparencia y el acceso a la información pública? ${ }^{7}$. El caso es ilustrativo por la etapa que inauguró en la apropiación del concepto de Parlamento Abierto tanto entre actores legislativos como entre ciudadanos y organizaciones de la sociedad civil, asociándolo intrínsecamente con una alta dosis de participación ciudadana ${ }^{8}$. El acompañamiento lo realizó un comité de expertos responsable de valorar la idoneidad de los aspirantes al cargo e integrar una lista con los mejores perfiles, de la que se eligió a los nuevos comisionados.

\section{Hacia una rendición ético-social de cuentas}

Arellano et al. (2018) definen la noción de rendición social de cuentas como aquella capacidad de la sociedad civil organizada de controlar e influir en las instituciones públicas. Como muestran estos autores, lo que le imprime un cariz social a la rendición de cuentas es la participación de actores sociales en el espacio público. Pero para que la contribución de la sociedad civil sea positiva es necesario considerar elementos de orden ético.

Aunque parezca contradictorio por la desafección social que conlleva, a la crisis de representatividad y de confianza en las instituciones del entorno político le corre en paralelo una emergencia de actores sociales interesados en la incidencia política. En el caso de México, pese a que la densidad asociativa es significativamente menor a la de otros países ${ }^{9}$, las organizaciones de la sociedad civil se han convertido en fuente de referencia en rubros como la defensa de los derechos humanos, el acceso a la justicia, la transparencia, la educación e, incluso, la seguridad pública. Son actores sociales que apuestan por la incidencia desde la vía institucional sin abandonar su desenvolvimiento en otros canales de participación como la protesta y la movilización social.

7 Este caso fue documentado en 2017 por el Grupo de Trabajo de Apertura Legislativa de la AGA y ParlAmericas junto con otras 11 experiencias latinoamericanas.

8 Informe del acompañamiento disponible en: http://www.senado.gob.mx/comisiones/ anticorrupcion/docs/ifai/Informe_designacion.pdf

9 El número de organizaciones de la sociedad civil en México es de 27 por cada 100.000 habitantes. En otros países este indicador se eleva hasta 24 veces, a saber: 270 en Argentina, 650 en Chile y 670 en Estados Unidos (Muñoz 2014). 


\subsection{Rendición de cuentas, un proceso relacional}

La rendición de cuentas es un componente central en las democracias representativas al ser uno de los instrumentos para controlar el poder delegado, donde reposa la legitimidad de estas. El gobernante ha de corresponder a la confianza otorgada por quienes lo eligieron representante, lo cual implica una relación entre unos actores que son mandantes y otros que son mandatarios. Los segundos actúan en nombre de los primeros, por lo que están obligados a rendir cuentas de lo que hacen o deciden en su nombre.

Rendición de cuentas es una traducción inexacta del término anglosajón accountability, relacionado con la obligación de reportar, explicar o justificar algo, o bien, ser responsable ante alguien de algo. Si accountability se deriva de account — cuenta, en español- su significado tiene que ver con la capacidad de dar cuentas, aunque en términos políticos denote sobre todo una obligación.

De acuerdo con Schedler (2006), la rendición de cuentas tiene dos elementos básicos: la obligación de los poderes públicos de informar sobre sus decisiones y justificarlas en público -lo que denomina answerability - y la capacidad de sancionar a sus integrantes por haber violado sus deberes públicos -enforcement-. En este sentido, la rendición de cuentas descansa sobre tres pilares: información, justificación y sanción, de donde se sigue que tiene tres dimensiones: informativa, explicativa y punitiva.

Explica Ugalde (2002) que no se trata de responsabilidad política, pues se puede ser responsable por algo sin ser responsable ante alguien; en todo caso la supone. Tampoco es solamente sensibilidad política, toda vez que esta es particularmente coyuntural. Asimismo, es más que control y fiscalización que, siendo ingredientes esenciales de un sistema de rendición de cuentas, no necesariamente abarcan las dimensiones informativa y explicativa.

La rendición de cuentas, entonces, es ante todo una relación que implica una responsabilidad previa. Así, hay siempre por lo menos dos sujetos involucrados con roles distintos, un asunto sobre el que se rinden cuentas, relacionado con una responsabilidad previa asumida, y un juicio o sanción.

Un aspecto relevante en las relaciones de rendición de cuentas es el factor temporal. Para algunos autores la rendición de cuentas es de carácter retrospectivo, pues las acciones de los gobernantes son evaluadas ex post. Otros argumentan que, si bien suelen ser ejercicios post facto, también es viable rendir cuentas sobre acciones futuras, tal es el caso de procesos de toma de decisiones 
que incluyen planes y programas de acción, o bien, discusiones de leyes y reformas en materia parlamentaria. En realidad, la rendición de cuentas ha de pensarse como una totalidad en la que es posible la participación social en tres momentos: antes, con una mirada prospectiva; durante, con una visión procesal; y después, con un énfasis retrospectivo.

En aras de lograr mayor claridad acerca de los actores de la rendición de cuentas y sus mecanismos, una clasificación tradicional es la que hace O’Donnell (2003) desde una lógica espacial, distinguiendo a la rendición de cuentas horizontal de la vertical. La primera se presenta al interior de la esfera estatal, e incluye el conjunto de mecanismos de control y vigilancia entre las agencias del Estado. La segunda tiene que ver con la existencia de controles externos sobre el gobierno, esto es, relaciones de control de la sociedad hacia el Estado, siendo el voto el mecanismo clásico que tienen los ciudadanos para exigir cuentas a sus gobernantes. Sin embargo, este no es el único medio al alcance de la sociedad para demandar rendición de cuentas. El acceso a la información pública, la movilización social y la presión mediática son otras formas de hacerlo, de ahí que, dentro de la rendición de cuentas vertical, o fuera de ella (Peruzzotti y Smulovitz 2002), sea pertinente ubicar a la rendición social de cuentas.

\subsection{La rendición social de cuentas}

La noción de rendición social de cuentas está asociada a la capacidad de la sociedad civil organizada de influir en la agenda de las instituciones públicas de manera directa o indirecta a través de la activación de mecanismos formales de rendición de cuentas, específicamente de tipo horizontal. Por esta razón, a la rendición social de cuentas se le asigna un carácter blando; no obstante, su potencial no es menor en el contexto de la crisis de representatividad y de la incidencia de actores sociales cada vez más exigentes en la esfera política. Sin ir muy lejos, el caso referido de Parlamento Abierto en México al final de la sección anterior da cuenta de un mecanismo de cogestión en el que actores estatales y sociales tomaron juntos decisiones con implicaciones institucionales.

Desde el punto de vista de las relaciones de rendición de cuentas vertical, la rendición social de cuentas es un complemento del voto. Además, abre la puerta para explorar e impulsar procesos deliberativos entre sociedad y gobierno, enriqueciendo así la democracia representativa con formas de la democracia participativa. 
Para Merino (2013), hoy en día no es concebible una democracia completa sin participación y representación, puesto que lo que en términos modernos se asume como democracia ya no es sólo la manera de acceder al poder, sino la forma de garantizar la responsabilidad de quienes lo hacen por medio de la vigilancia, y el mejor modo para incentivar la participación de los ciudadanos es mediante una política amplia y diversa de rendición de cuentas. La participación ciudadana y su capacidad de influir en los estrechos límites de la representación es, de hecho, una veta fundamental para abordar la calidad de una democracia; de tal suerte que los procesos de rendición social de cuentas son un indicador de la manera en que las democracias distribuyen el poder (López e Hincapié 2014).

La rendición social de cuentas reúne un conjunto variado de iniciativas y formas alternas de control político. Es un mecanismo:

basado en las acciones de un amplio espectro de asociaciones y movimientos ciudadanos, así como también en operaciones mediáticas. Las iniciativas de estos actores tienen por objeto monitorear el comportamiento de los funcionarios públicos, exponer y denunciar actos ilegales de estos y activar la operación de agencias horizontales de control. (Peruzzotti y Smulovitz 2002, 32)

Esta definición anticipa que la rendición social de cuentas como forma de politización puede desarrollarse por vías institucionales y no institucionales. De acuerdo con los autores citados, el principal recurso de los actores sociales colectivos es su intensidad y la visibilidad de su voz, de ahí que estén a su alcance tanto costos reputacionales como implicaciones legales.

Según Ackerman (2005), los mecanismos de rendición social de cuentas pueden identificarse, entre otras categorías, por la profundidad y la inclusión de la participación. Sobre la primera, señala que la mayoría de las iniciativas pro rendición de cuentas que se promueven desde el Estado tienden a ser poco institucionalizadas, involucrando poco a la sociedad civil organizada en los procesos de toma de decisiones. Por lo que toca a la inclusión de la participación, el autor advierte acerca del riesgo que supone incluir únicamente a un grupo selecto de organizaciones de la sociedad civil, en detrimento de otras con un nivel de discusión cuyo procesamiento resulte más complejo.

Una noción útil para el análisis del Parlamento Abierto como espacio de colaboración y cocreación entre el Estado y la sociedad es la de interfaz socioestatal, acuñada por Isunza (2006, 269). Para este autor, 
son interfaces socioestatales aquellas en las que la sociedad civil y el Estado se relacionan en espacios de participación, interpelación y control del poder estatal.

Tabla 1

Tipos cognoscitivos y políticos de interfaces socioestatales

\begin{tabular}{|c|c|c|}
\hline Bien base del intercambio & Gramática del intercambio & Tipo de interfaz \\
\hline \multirow{3}{*}{ Información } & Sociedad informa al Estado & Contribución \\
\hline & Sociedad es informada por el Estado & Transparencia \\
\hline & $\begin{array}{l}\text { Sociedad y Estado se informan } \\
\text { mutuamente }\end{array}$ & Comunicativa \\
\hline \multirow{3}{*}{ Poder } & Sociedad manda al Estado & Mandataria \\
\hline & Sociedad es mandada por el Estado & Transferencia \\
\hline & $\begin{array}{l}\text { Sociedad y Estado se mandan } \\
\text { mutuamente }\end{array}$ & Cogestiva \\
\hline
\end{tabular}

Fuente: Elaboración propia con base en Isunza (2006) e Isunza y Gurza (2010).

Con base en esta tipología, al Parlamento Abierto se le puede concebir como una interfaz que varía y crece en función de sus niveles de institucionalización, independientemente de sus contenidos.

\subsection{Rendir cuentas desde una perspectiva ética}

Siguiendo el camino trazado por Arellano et al. (2018), en este trabajo se perfila una variante de rendición ético-social de cuentas desde los conceptos de responsabilidad, representación y deliberación, a manera de contenido ético.

Debido a que no es toda la sociedad la que se moviliza y decide participar activamente en los asuntos públicos, sino grupos concretos cuya legitimidad depende del tipo de relación que establecen con los intereses y las personas que representan, Isunza y Gurza (2010) plantean la doble faz de la rendición de cuentas como método para subsanar esta relación indirecta. Estos autores sostienen que es la 
propia rendición de cuentas la que elabora la legitimidad de las prácticas de representación, haciéndola:

dependiente de un proceso que se desdobla en el tiempo y no de un acto inicial de consentimiento, pues si el control por parte de los eventuales beneficiarios implica el conocimiento de la representación presuntiva ejercida en su nombre, la reiteración o renovación del control supone reconocimiento, confiere legitimidad (Izunza y Gurza 2010, 44).

La sociedad civil organizada actúa en representación de grupos sociales y esto amplía los alcances de la rendición social de cuentas hacia los controles sociales de los representados sobre los controladores, abriendo paso a la consideración ética por los peligros de la participación ciudadana; entre ellos, la conformación de élites sociales que marginan otro tipo de expresión ciudadana, la exclusión del debate público de sectores con poca o nula capacidad organizativa, y la inercia de vislumbrar que toda participación ciudadana es positiva en sí misma, cuando a veces predominan los intereses particulares (Canto 2005).

Para prevenir estos riesgos se sugiere echar mano de tres conceptos con sustrato ético que interpelan directamente los alcances del Parlamento Abierto como mecanismo de rendición social de cuentas: responsabilidad, representación y deliberación.

Asociado a la idea de poder, el concepto de responsabilidad atañe a la sociedad civil organizada por su capacidad de incidencia política. La responsabilidad puede acotarse estrictamente al ámbito de lo privado; sin embargo, una perspectiva más comunitaria la ensancha a quienes forman parte del grupo al que se pertenece. Dando un paso más, la responsabilidad puede extenderse con respecto a quienes son víctimas de una injusticia estructural (Young 2005). La responsabilidad colectiva es «el modo en que los sujetos participan o se incorporan a un designio aceptado por el grupo, y lo hacen suyo como designio colectivo» (Cruz 2015, 108).

La idea de representación está estrechamente unida a la noción de justicia con implicaciones políticas. En Fraser (2015), la representación supone una dimensión de la justicia inseparable de las exigencias de distribución y reconocimiento, ligada a la capacidad de influir en el debate público y en la toma de decisiones. Vista desde los actores sociales, la representación puede catapultar luchas cuyo origen son injusticias sociales, dando cabida a grupos usualmente excluidos del debate público. La injusticia política se presenta como 
una representación fallida, no sólo de la institución parlamentaria, sino de quienes actúan por poder, interés o capacidad colectiva en defensa de otros grupos.

En referencia a la deliberación corresponde tener presente que, de suyo, todo mecanismo de rendición social de cuentas supone formas deliberativas de participación y posibilita la tematización de nuevos problemas en la agenda pública (Peruzzotti 2006). Son quizá las condiciones deliberativas de participación las que más constriñen al Parlamento Abierto por su naturaleza, incluyendo la meta-deliberación, es decir, la forma en la que legisladores y actores sociales se ponen de acuerdo en las formas en las que se discute un asunto. En la democracia deliberativa, la legitimidad democrática radica en la aceptación pública de las razones que motivan una decisión política.

Esta triada resulta útil con miras a identificar las condiciones bajo las cuales el Parlamento Abierto puede ser un mecanismo efectivo de rendición ético-social de cuentas, las cuales se aplicarán al caso de estudio.

\section{El futuro de la seguridad en México en Parlamento Abierto}

A diferencia del caso referido al final de la primera sección u otros más en los últimos años, como la elaboración conjunta sociedadEstado de la Ley General de Transparencia y Acceso a la Información Pública —emblemáticos por la efectiva incidencia de actores sociales en decisiones legislativas-, es posible distinguir otros casos en los que la práctica del Parlamento Abierto no ha tenido el mismo desenlace. Que el Parlamento Abierto pueda tener un impacto relevante en el empoderamiento de actores sociales, sobre las políticas públicas en las que interviene y en una cultura política cada vez más deliberativa, pende de una senda de institucionalización que puede contribuir a que tenga un carácter temporal continuo (Arellano et al. 2018).

En este tenor es que se analiza el papel del colectivo Seguridad Sin Guerra (SSG) en la discusión legislativa sobre el combate al narcotráfico y al crimen organizado en México, una discusión desarrollada entre 2017 y 2019 bajo dinámicas de Parlamento Abierto, que se resumen a continuación. 
Tabla 2

\section{Contexto y momentos clave de la discusión legislativa sobre la seguridad en México}

\begin{tabular}{|c|c|}
\hline Diciembre 2006 & $\begin{array}{l}\text { Inicio de la guerra contra el narcotráfico y el crimen orga- } \\
\text { nizado. }\end{array}$ \\
\hline \multirow[t]{2}{*}{ Noviembre 2016} & $\begin{array}{l}\text { Exigencia de la Secretaría de la Defensa Nacional que dio } \\
\text { lugar a la Ley de Seguridad Interior, demandando un mar- } \\
\text { co normativo para regularizar la participación de las Fuer- } \\
\text { zas Armadas en tareas de seguridad pública. }\end{array}$ \\
\hline & Conformación del colectivo Seguridad Sin Guerra. \\
\hline Diciembre 2017 & $\begin{array}{l}\text { Aprobación en el Congreso de la Unión de la Ley de Segu- } \\
\text { ridad Interior. }\end{array}$ \\
\hline \multirow[t]{2}{*}{ Noviembre 2018} & $\begin{array}{l}\text { Declaración de inconstitucionalidad de la Ley de Seguridad } \\
\text { Interior por parte de la Suprema Corte de Justicia de la } \\
\text { Nación. }\end{array}$ \\
\hline & $\begin{array}{l}\text { Anuncio de la creación de la Guardia Nacional por el presi- } \\
\text { dente electo Andrés Manuel López Obrador. }\end{array}$ \\
\hline Febrero 2019 & $\begin{array}{l}\text { Aprobación en el Congreso de la Unión de la reforma } \\
\text { constitucional que creó la Guardia Nacional. }\end{array}$ \\
\hline
\end{tabular}

Fuente: Elaboración propia.

\subsection{La apuesta por la militarización}

A una década del inicio de la guerra contra el narcotráfico declarada por el expresidente Felipe Calderón Hinojosa, tuvo lugar la discusión legislativa en orden a proporcionarle a las Fuerzas Armadas un marco legal para su operación. El despliegue militar que inició en 2006 ha sido seriamente cuestionado, pues la cifra de homicidios ha ido al alza y ha aumentado también el número de denuncias por violaciones a los derechos humanos cometidas por las Fuerzas Armadas.

La tasa de homicidios que en 2007 era de ocho por cada 100.000 habitantes incrementó a 23 en 2018, año en el que se registraron 33.743 homicidios dolosos según cifras oficiales ${ }^{10}$. Por otra parte, las

10 Datos del Secretariado Ejecutivo del Sistema Nacional de Seguridad Pública. 
denuncias en contra de militares y marinos confirman que la ofensiva castrense ha fracasado. De 2007 a 2017, la Comisión Nacional de los Derechos Humanos emitió un total de 130 recomendaciones a la Secretaría de la Defensa Nacional (Sedena) y a la Secretaría de Marina por violaciones graves a derechos humanos, entre ellas, tortura, tortura sexual, desapariciones forzadas y ejecuciones extrajudiciales.

Pese a que la administración de Peña Nieto quiso alejarse de la narrativa bélica para combatir al narcotráfico, durante su gobierno no sólo se dio continuidad a la estrategia, sino que este culminó con la exigencia de las Fuerzas Armadas de contar con un marco jurídico para legalizar su actuación. ${ }^{11}$ La Ley de Seguridad Interior (LSI) que satisfizo este anhelo fue aprobada al concluir el quinto año del sexenio de Peña Nieto, convirtiéndose en las semanas posteriores en la ley más impugnada ante la Suprema Corte de Justicia de la Nación en la historia del país.

El 15 de noviembre de 2018, a casi un año de su aprobación, la Corte declaró inconstitucional la LSI arguyendo que el Congreso de la Unión no tenía facultades para legislar en materia de seguridad pública ${ }^{12}$, que se abría la puerta a la normalización de la intervención del Ejército en tareas de seguridad pública, y que el proceso de aprobación se había seguido de prisa, en detrimento de la deliberación democrática. Inesperadamente, la misma semana y a unos días de tomar posesión como presidente de México, López Obrador propuso la creación de una Guardia Nacional (GN) a cargo de las Fuerzas Armadas como instrumento para combatir la delincuencia organizada al presentar su Plan Nacional de Paz y Seguridad. A pesar de que durante su campaña se comprometió a encauzar un cambio profundo en la estrategia de seguridad que incluía el regreso de los militares a sus cuarteles, López Obrador inició su gobierno anunciando una reforma a la Constitución para hacer legal lo que la Corte había declarado ilegal.

\subsection{Movilización social en torno a la Ley de Seguridad Interior}

Hacia finales de 2016, frente a la recepción en el Congreso de la Unión del emplazamiento para legalizar la actuación del Ejército en las calles, se conformó el colectivo SSG. Este colectivo se integró con

11 A finales de 2016, tras un reclamo del titular de la Sedena por un ataque contra efectivos del Ejército, el Congreso de la Unión inició la discusión (Centro Prodh 2018).

12 Se optó por el concepto «seguridad interior» para hacer $k$ pasar las funciones de seguridad pública por tareas de seguridad interior. 
aproximadamente 300 organizaciones de la sociedad civil y personas especialistas en el ámbito de la seguridad pública, académicos, ciudadanos y víctimas, bajo la convicción de evitar la perpetuación del modelo de seguridad basado en la acción militar ${ }^{13}$. Son dos momentos los que son objeto del análisis bajo las lentes éticas de la responsabilidad, la representación y la deliberación: la discusión previa a la aprobación en diciembre de 2017 de la LSI y la discusión previa a la aprobación en febrero de 2019 de la reforma constitucional con la que se creó la GN.

Si bien la LSI fue aprobada en diciembre de 2017, en los primeros meses de ese año comenzó la discusión de seis iniciativas que coincidían en facultar al Ejecutivo federal a ordenar el despliegue militar sin controles civiles. Desde el mes de enero, el Senado convocó a especialistas y representantes de organizaciones y organismos de derechos humanos para evaluar el tema desde esta perspectiva, razonándose que la seguridad pública es competencia exclusiva de las autoridades civiles.

De acuerdo con el Centro Prodh (2018), esta organización y otras más integrantes del colectivo SSG expusieron en febrero de 2017 los peligros de la LSI, junto con evidencia que indicaba que la actividad del Ejército había abonado a la violencia, por lo que desde ese momento el llamado se sintetizó en la expresión «legislar con evidencia». Por contra, el proceso de discusión legislativa empezó a conducirse con formas poco democráticas, siendo convocados los legisladores a las instalaciones de las Fuerzas Armadas, y no al revés, a escuchar sus planteamientos. Con este telón de fondo, el colectivo SSG criticó que el proyecto de ley no tomaba en cuenta los efectos negativos de la estrategia de seguridad iniciada en 2006.

Durante los meses posteriores, el colectivo SSG continuó alertando sobre el riesgo de la LSI, siendo hasta noviembre de 2017 que, nuevamente, un reclamo del titular de la Sedena revivió la discusión legislativa, haciendo eco del exhorto el mismo presidente Peña Nieto y, con ello, la bancada del PRI, a la que pronto se le unió la bancada de oposición del PAN.

Ante ello, el colectivo SSG denunció el intento de legislar de forma precipitada, a un par de semanas que concluyera el periodo legislativo. No obstante, la discusión reinició formalmente en la Cámara de Diputados el 30 de noviembre, donde se aprobó la LSI en un

13 Buena parte de su incidencia ha sido recopilada en el sitio web: https://www. seguridadsinguerra.org/ 
día, turnándose al Senado para su validación. El 1 de diciembre se registraron las primeras protestas en las calles. El 5 de diciembre, el colectivo SSG acudió al Senado a presentar miles de firmas en contra de la LSI; en tanto, el Alto Comisionado de la ONU para los Derechos Humanos pidió al Senado no aprobar la LSI, llamado al que se sumaron algunos organismos autónomos en el país. La petición era clara: ampliar el diálogo.

En respuesta, el entonces presidente solicitó al Senado profundizar en el diálogo con la sociedad civil, convocándose a diferentes mesas de análisis con gobernadores, alcaldes, académicos y activistas. Integrantes del colectivo SSG proyectaron afuera del Senado un documental sobre la violencia en México y exhortaron a los legisladores a ahondar en la discusión. La presión y la movilización derivaron en modificaciones en el proyecto aprobado por la Cámara de Diputados; sin embargo, no fueron cambios sustantivos, lo que llevó al colectivo SSG el 13 de diciembre a acusar un diálogo simulado. Con todo, el proceso legislativo siguió y en la madrugada del 15 de diciembre se aprobó en el Senado la LSI, regresando a la Cámara de Diputados por las modificaciones hechas en 10 artículos. Los cambios se avalaron el mismo día en una sesión en la que se dispensaron los trámites para votar la ley de manera expedita.

\subsection{Participación ciudadana y audiencias públicas: la Guardia Nacional}

El propósito de la LSI invalidada por la Corte fue recuperado bajo la forma de una GN con reformas a la Constitución. La iniciativa fue presentada el 20 de noviembre de 2018 por diputados de Morena, el partido político que llevó a López Obrador a la Presidencia.

A diferencia del proceso legislativo que se siguió con la LSI, en este caso se programaron audiencias públicas en la Cámara de Diputados desde un inicio. En el marco del arranque del nuevo gobierno, el contexto de exigencia generado por el debate público en torno a la militarización del país propició esta apertura, en la que participaron representantes de organismos internacionales de derechos humanos, especialistas, académicos, organizaciones y colectivos de la sociedad civil.

Considerando la experiencia previa de diálogo en el Senado, el colectivo SSG se pronunció el 7 de enero de 2019 por audiencias efectivas a través de una metodología para las mismas, criticando fuertemente el desprecio a la evidencia en la discusión legislativa sobre la LSI. La metodología propuesta incluía que en las audiencias se 
adoptara un cuestionario hecho por el colectivo, se instalara un comité ciudadano de acompañamiento y se convocara a víctimas.

La voz de quienes han padecido excesos de las Fuerzas Armadas y/o buscan a sus seres amados, es necesaria en el desarrollo del debate público, para que el mismo sea considerado suficiente. Legislar con evidencia y en Parlamento Abierto es más necesario que nunca. (Seguridad Sin Guerra 2019, 28)

El 8 de enero, la Cámara de Diputados accedió a que el cuestionario sirviera como guía y a invitar a víctimas a las audiencias, al tiempo de sostener que no era posible poner en marcha un comité de acompañamiento. El colectivo, no obstante, realizó esta labor por su cuenta. Las audiencias se realizaron del 8 al 12 de enero y en ellas participaron gobernadores, alcaldes, secretarios de Estado, representantes de organismos internacionales de derechos humanos, investigadores, especialistas, activistas, representantes de organizaciones de la sociedad civil y de organismos empresariales. Pese a lo comprometido, las víctimas fueron excluidas y el formato de las audiencias fue definido por la Cámara de Diputados.

Ante la evidencia, en las audiencias se concluyó que el dictamen no podía ser aprobado en sus términos, siendo esencial que el mando de la GN fuera civil y no militar. A juicio del colectivo SSG (2019), el tema del mando civil no agotaba la problemática, aunque fue crucial en la discusión. Finalmente, la Cámara de Diputados aprobó el 16 de enero la reforma constitucional de la GN con un mando compartido entre civiles y militares por medio de una junta de jefes.

En el Senado, cámara revisora, se acordó también que la discusión se llevara a cabo en Parlamento Abierto. En realidad, por los números necesarios para hacer avanzar la reforma constitucional, el partido mayoritario, Morena, se vio obligado a negociar con la oposición esta condición, así como la de un mando civil y una actuación temporal para las Fuerzas Armadas. Las audiencias públicas en el Senado ocurrieron del 11 al 15 de febrero, nuevamente, bajo un formato definido por los legisladores.

En las audiencias participaron otra vez representantes de organismos internacionales de derechos humanos, académicos, especialistas, gobernadores, alcaldes, representantes de organizaciones de la sociedad civil, defensores de derechos humanos y, esta vez sí, víctimas de la violencia del Estado. La discusión finalizó con un acuerdo unánime entre todas las fuerzas políticas en torno a un mando y carácter civil para la GN, y una temporalidad de cinco años para las Fuerzas Armadas 
en tareas de seguridad pública. El voto fue unánime en el Senado el 21 de febrero y casi unánime en la Cámara de Diputados el 28 de febrero, pasando a los congresos estatales para su validación. El Parlamento Abierto, sin embargo, no llegó para quedarse, meses después no lo hubo para la discusión de las leyes reglamentarias de la GN.

4.4. Responsabilidad, representación y deliberación en la discusión de la LSI y la creación de la GN

Pensar éticamente el Parlamento Abierto requiere ir más allá de su capacidad de ejercer control e influir en las instituciones públicas. La variable ética le exige a este instrumento concebirse desde un plano distinto y orientar su contenido. No siendo únicos ni definitivos, pero sí estratégicos para conducirlo dentro de cauces éticos, el presente análisis recurre a los tres conceptos ya expuestos, desdoblando cada uno en un par de criterios.

Tabla 3

Marco analítico para un mecanismo de rendición ético-social de cuentas

\begin{tabular}{|c|c|c|c|}
\hline Variables & Responsabilidad & Representación & Deliberación \\
\hline \multirow{2}{*}{ Criterios } & $\begin{array}{c}\text { Vulnerabilidad e } \\
\text { injusticia estructural }\end{array}$ & Justicia política & Inclusión \\
\cline { 2 - 4 } & Sentido colectivo & $\begin{array}{c}\text { Doble faz de } \\
\text { rendición de cuentas }\end{array}$ & $\begin{array}{c}\text { Condiciones de } \\
\text { deliberación }\end{array}$ \\
\hline
\end{tabular}

Fuente: Elaboración propia.

Por haberse llevado a cabo en un contexto de movilización social propio de los mecanismos de rendición social de cuentas y bajo prácticas del Parlamento Abierto como las audiencias públicas, es posible analizar desde esta óptica el papel del colectivo SSG.

Siguiendo una visión más ancha de la noción de responsabilidad, la movilización social en contra de la militarización de la seguridad en México puede enmarcarse en una perspectiva de hacerse cargo de la injusticia estructural expresada en términos de violencia e inseguridad. Según la narración de su actividad durante la discusión de la LSI y de la GN, una constante en la incidencia del colectivo SSG fue su 
preocupación por poner al centro a las víctimas, acompañadas por organizaciones y organismos que han caminado junto a ellas.

En el caso analizado, las víctimas se han implicado en acciones directas tendientes a transformar su situación (Young 2005), siendo la injusticia estructural la que ha detonado que actores sociales hayan asumido una responsabilidad en orden a revertirla, en buena medida por su condición de poder, interés y capacidad colectiva (Young 2011). El poder compartido de organizaciones, instituciones y ciudadanos en lo individual agrupados en el colectivo SSG se tradujo en una causa común: pugnar por una seguridad en manos de instituciones civiles, mirando a quienes han padecido sus efectos y por el futuro de la sociedad en su conjunto.

Tratándose de la institución parlamentaria y de organizaciones de la sociedad civil, la representación que corona una comprensión tridimensional de la justicia es imprescindible para garantizar una impronta ética, más aún en el caso de los actores sociales que representan causas propias y las de otros actores que no necesariamente tienen la capacidad de incidir en el parlamento. Entendiendo la justicia como paridad de participación (Fraser 2015), la representación es vital para asegurar el control social.

La injusticia estructural a la que ya se hacía referencia por razones de la expansión de la violencia criminal en México es aún más profunda si se le agregan los déficits en materia de distribución y reconocimiento (Fraser 2010). En este contexto también cruzado por una crisis de representatividad que afecta la confianza ciudadana, han sido organizaciones de la sociedad civil, instituciones académicas y organismos internacionales de derechos humanos quienes se han posicionado políticamente y han influido en el debate público, siendo el caso del colectivo SSG. Acerca de la representación social ejercida por el colectivo, fue clave para favorecer el control social sobre sí mismo su relación directa con víctimas, así como su composición amplia y plural.

La deliberación fue quizá el elemento más presente y a la vez ausente en la discusión de la LSI y de la GN bajo los principios del Parlamento Abierto. Tomándolos como guía, la discusión registró condiciones poco propicias para un debate plenamente abierto, como lo denunció el colectivo SSG. Por lo que hace a la participación ciudadana, la discusión se distinguió por una elevada capacidad de involucramiento de la sociedad civil tanto con expresiones de protesta como con propuestas argumentativamente sólidas; de igual modo pudo constatarse un nivel de inclusión significativo de los afectados. 
En relación con la colaboración, fue la institución parlamentaria en sus dos recintos la que restringió un esquema de cocreación, quedando limitada la interacción a una interfaz de contribución ${ }^{14}$ con impacto diferenciado: en la discusión de la LSI el Congreso se resistió a considerar los argumentos de la sociedad civil, mientras que en la discusión de la GN el impacto fue mayor. Desde los principios del Parlamento Abierto las condiciones de deliberación fueron suficientes mas no óptimas. La falta de una colaboración más institucionalizada entre la sociedad civil organizada y los legisladores impidió que la meta-deliberación fuera decidida en común.

\section{Conclusiones}

La crisis de representatividad que atraviesa México justifica la necesidad de pensar en fórmulas innovadoras tendientes a construir confianza y legitimidad. No son signos alentadores que sólo cuatro de cada diez mexicanos apoyen la democracia y que otros cuatro del mismo conjunto sean indiferentes al tipo de régimen. Los niveles de desconfianza no parecen ser convenientes.

Ante los límites de la representatividad, la ruta hacia una posible profundización de la democracia pasa por la creación e institucionalización de espacios deliberativos que puedan agregarle sustancia. Este camino ha permitido repensar la acción pública hacia un paradigma en el que la relación entre gobierno y sociedad sea más colaborativa. Los espacios de interacción socioestatal pueden ser tan variados como distintos sean los recursos que se intercambian y su direccionalidad.

En el caso del Parlamento Abierto, los casos aludidos en este trabajo confirman que los efectos de su práctica dependen de su institucionalización. La interfaz cogestiva, acaso indicativa de un intercambio con una potencialidad importante por la capacidad de mandarse mutuamente sociedad y Estado, es equivalente al ideal de colaboración de la nueva concepción de gobierno abierto enunciado en la noción de cocreación, que supone como precondición garantías de transparencia, participación y rendición de cuentas.

El parlamento es una institución celosa de la legitimidad que le confiere el voto popular, reacio a que ciudadanos no electos y organizaciones sociales cuya representación no la acredita el sufragio, participen en la toma de decisiones. La reducción del Parlamento

14 Se da cuando la sociedad informa al Estado. 
Abierto a la dimensión de transparencia legislativa ejemplifica la resistencia a dar un paso más.

En las experiencias de Parlamento Abierto en México no se identifica una voluntad de desplazar o sustituir a la autoridad legitimada para la toma de decisiones en el ámbito legislativo, sí, en cambio, una aspiración a contribuir responsablemente en la discusión de iniciativas de ley o proyectos de reforma, así como en procesos de designación o control de otros poderes a fin de aportar mayor legitimidad al quehacer legislativo. Así, la acción ciudadana que exige más de sus instituciones puede encontrar en espacios como el Parlamento Abierto un vehículo efectivo para coadyuvar en la eficacia de las instituciones públicas.

Como mecanismo de rendición de cuentas, el Parlamento Abierto enfrenta un reto mayúsculo al incentivar la participación de la sociedad civil organizada en el Poder Legislativo. Debido a que la participación ciudadana no es positiva en sí misma en términos éticos, resulta fundamental un examen que ayude a asegurar que la agencia de ciudadanos y organizaciones sociales se conduzca por cauces con ese talante.

Como se ha dicho, en un primer nivel la sociedad civil organizada participa en una relación de rendición de cuentas como aquel actor que exige la explicación y la justificación de los legisladores en cuanto a las decisiones que toman o están por tomar. En un segundo nivel, es la sociedad civil organizada la que evita que las relaciones de rendición de cuentas de tipo horizontal entre los poderes Ejecutivo y Legislativo sucedan de espaldas al espacio público. Por ello es que la relación de rendición de cuentas que mejor explica la movilización social y ciudadana alrededor de la discusión analizada es la de tipo social, pues no sólo activó mecanismos de la rendición de cuentas horizontal, sino que influyó en el resultado de la política en materia de seguridad en el país por la vía institucional —audiencias públicas - y la no institucional - presión social一.

El análisis del Parlamento Abierto como mecanismo de rendición ético-social de cuentas ha de pasar por una revisión de criterios y elementos con sustrato ético, tales como la responsabilidad, la representación y la deliberación. Es bajo condiciones como estas que puede constituirse realmente como un mecanismo efectivo de este tipo de rendición de cuentas. La participación de organizaciones de la sociedad civil y ciudadanos en lo individual de distintos campos en el colectivo SSG, ha sido testimonial de un compromiso ético que trasciende la propia responsabilidad, la auto-representación y las herramientas personales de deliberación para incorporar el dolor de las víctimas, así como la transparencia en su relación con ellas, en su 
capacidad de influencia. Dados los alcances limitados de este trabajo, futuros análisis podrían ahondar en esta orientación con la aplicación de entrevistas tanto a actores sociales como políticos.

La insistencia del colectivo SSG tanto en el formato del Parlamento Abierto como en la presencia y la participación de las víctimas en él, ha hecho las veces de un mecanismo adicional de rendición de cuentas ante el carácter representativo -asumido- de causas y preocupaciones generales, no sólo las de los actores que lo integran. Esto ha abonado en su empoderamiento $y$, a la par, en su legitimidad como colectivo, motivando una red compleja de rendición de cuentas que permite introducir la variante ética. Además de tener presentes los criterios éticos en su activación, no siendo los tres analizados los únicos, el Parlamento Abierto tiene por delante el desafío de su institucionalización, sin la cual difícilmente podrá evitar la disparidad de sus efectos, pero más relevante aún, impactar eficazmente en una cultura política más deliberativa.

\section{Bibliografía}

Ackerman, John. 2005. Social Accountability in the Public Sector. A Conceptual Discussion. Washington, DC: World Bank.

Aguilar, Inma. 2014. "Ciberactivismo y Parlamento: movimientos sociales e iniciativas ciudadanas por la transparencia y la participación». En Parlamentos abiertos. Tecnología y redes para la democracia, coordinado por Rafael Rubio, 323-361. Madrid: Congreso de los Diputados.

Aranda, Elviro. 2017. «Parlamento abierto: una visión desde los principios de funcionamiento de las cámaras parlamentarias». Revista Española de Derecho Constitucional 111: 13-43.

Arellano, Javier et al. 2018. Rendición de cuentas social y participación. Bilbao: Alboan.

Beetham, David. 2006. El parlamento y la democracia en el siglo veintiuno. Una guía de buenas prácticas. Ginebra: Unión Interparlamentaria.

Canto, Manuel. 2005. "Las políticas públicas participativas, las organizaciones de base y la construcción de espacios públicos de concertación local». Acceso el 4 de abril de 2019. https://studylib.es/doc/7661526/laspol\%C3\%ADticas-p\%C3\%BAblicas-participativas--las-organizaciones...

Centro Prodh. 2018. Perpetuar el fallido modelo de seguridad. La aprobación de la Ley de Seguridad Interior y el legado de una década de políticas de seguridad en México contrarias a los derechos humanos. México, D.F.: Centro de Derechos Humanos Miguel Agustín Pro Juárez.

Corporación Latinobarómetro. 2018. Informe 2018. Santiago: Corporación Latinobarómetro. Acceso el 4 de abril de 2019. http://www.latinobarometro. org/lat.jsp 
Cruz, Manuel. 2015. Hacerse cargo. Por una responsabilidad fuerte y unas identidades débiles. Barcelona: Gedisa.

Cruz-Rubio, César. 2015. "¿Qué es (y qué no es) gobierno abierto? Una discusión conceptual». Eunomía. Revista en Cultura de la Legalidad 8: 37-53.

Fraser, Nancy. 2015. Fortunas del feminismo. Quito: Instituto de Altos Estudios Nacionales del Ecuador.

Fraser, Nancy. 2010. Scales of justice. Nueva York: Columbia University Press.

González, Alejandro. 2016. Gobierno abierto. México, D.F.: INAI.

Gutiérrez-Rubí, Antoni. 2014. «Parlamento abierto y política de proximidad». En Parlamentos abiertos. Tecnología y redes para la democracia, coordinado por Rafael Rubio, 363-388. Madrid: Congreso de los Diputados.

Isunza, Ernesto. 2006. "Para analizar los procesos de democratización: interfaces socioestatales, proyectos políticos y rendición de cuentas». En Democratización, rendición de cuentas y sociedad civil: participación ciudadana y control social, coordinado por Ernesto Isunza y Alberto Olvera, 265-291. México, D.F.: Cámara de Diputados, CIESAS, Universidad Veracruzana y Miguel Ángel Porrúa.

Isunza, Ernesto y Adrián Gurza. 2010. «Precisiones conceptuales para el debate contemporáneo sobre la innovación democrática: participación, controles sociales y representación». En La innovación democrática en América Latina. Tramas y nudos de la representación, la participación y el control social, coordinado por Ernesto Isunza y Adrián Gurza, 17-80. México, D.F.: CIESAS y Universidad Veracruzana.

López, Jairo y Sandra Hincapié. 2014. "La rendición social de cuentas en la calidad de la democracia. Una discusión sobre aportes y retos de la política comparada». Reflexión política 16: 6-17.

Mariñez, Freddy. 2016. «Parlamento abierto y democracia: un debate sobre lo más allá de la poliarquía». Estudos de Administração e Sociedade 1: 9-28.

Merino, Mauricio. 2013. "La otra mirada de la democracia». En Rendición de cuentas social en México. Evaluación y control desde la sociedad civil, 12-15. México, D.F.: Secretaría de Contraloría y Transparencia Gubernamental del Gobierno del Estado de Oaxaca.

Mitofsky. 2019. Ranking Mitofsky en México: Confianza en Instituciones 2019. Acceso el 7 de abril de 2020. http://actualizar.consulta.mx/index.php/ encuestas-e-investigaciones/item/1309-mexico-confianza-en-instituciones2019

Muñoz, Humberto. 2014. Entramado entrampado institucional de las organizaciones de la sociedad civil en México. México, D.F.: Cemefi.

O'Donnell, Guillermo. 2003. "Horizontal Accountability. The Legal Institutionalization of Mistrust». En Accountability, Democratic Governance and Political Institutions in Latin America, editado por Scott Mainwaring y Christopher Welna, 34-54. Oxford: Oxford University Press.

Opening Parliament. 2012. Declaración sobre Transparencia Parlamentaria. Acceso el 17 de abril de 2019. http://openingparliament.s3.amazonaws. com/docs/declaration/1.0/spanish.pdf 
ParlAmericas. 2018. Documento de trabajo. Guía para desarrollar un Plan de Acción de Parlamento Abierto. Acceso el 18 de abril de 2019. http:// parlamericas.org/uploads/documents/Working_Document_Nov\%2029_ SPA_clean.pdf

ParlAmericas. 2017. Participación ciudadana en el proceso legislativo. Acceso el 18 de abril de 2019. http://parlamericas.org/uploads/documents/Kit\%20 de\%20herramientas_Participaci\%C3\%B3n\%20ciudadana\%20en \%20 el\%20proceso\%20legislativo.pdf

Peruzzotti, Enrique. 2006. "La política de accountability social en América Latina». En Democratización, rendición de cuentas y sociedad civil: participación ciudadana y control social, coordinado por Ernesto Isunza y Alberto Olvera, 245-264. México, D.F.: Cámara de Diputados, CIESAS, Universidad Veracruzana y Miguel Ángel Porrúa.

Peruzzotti, Enrique y Catalina Smulovitz. 2002. "Accountability social, la otra cara del control». En Controlando la política. Ciudadanos y medios en las nuevas democracias, editado por Enrique Peruzzotti y Catalina Smulovitz, 23-85. Buenos Aires: Temas.

Puente, Khemvirg e Issa Luna. 2018. Transparencia y apertura de la Cámara de Diputados de México. Observatorio de Transparencia Legislativa y Parlamento Abierto. México, D.F.: INAI y UNAM.

Ramírez-Alujas, Álvaro. 2010. «Innovación en la Gestión Pública y Open Government (gobierno abierto): una vieja nueva idea». Buen Gobierno 9: 93-133.

Rubio, Rafael. 2014. «Knocking on the Parliaments Door (Parlamentos digitales en la era de la participación)». En Parlamentos abiertos. Tecnología y redes para la democracia, coordinado por Rafael Rubio, 389-418. Madrid: Congreso de los Diputados.

Schedler, Andreas. 2006. ¿Qué es la rendición de cuentas? México, D.F.: IFAl.

Secretariado Técnico Tripartita. 2016. Plan de Acción 2016-2018 de México en la Alianza para el Gobierno Abierto. Acceso el 9 de abril de 2019. https:// www.gob.mx/cms/uploads/docs/Plan-de-Accion-2016-2018.pdf

Seguridad Sin Guerra. 2019. Informe Ciudadano sobre el proceso legislativo de la Guardia Nacional. México, D.F.: Seguridad Sin Guerra.

Ugalde, Luis. 2002. Rendición de cuentas y democracia. El caso de México. México, D.F.: IFE.

Young Iris. 2011. Responsabilidad por la justicia. Madrid: Morata.

Young, Iris. 2005. "Responsabilidad y justicia global: un modelo de conexión social». Anales de la Cátedra Francisco Suárez 39: 689-708. 


\section{Copyright}

Deusto Journal of Human Rights / Revista Deusto de Derechos Humanos is an Open Access journal; which means that it is free for full and immediate access, reading, search, download, distribution, and reuse in any medium only for non-commercial purposes and in accordance with any applicable copyright legislation, without prior permission from the copyright holder (University of Deusto) or the author; provided the original work and publication source are properly cited (Issue number, year, pages and DOI if applicable) and any changes to the original are clearly indicated. Any other use of its content in any medium or format, now known or developed in the future, requires prior written permission of the copyright holder.

\section{Derechos de autoría}

Deusto Journal of Human Rights / Revista Deusto de Derechos Humanos es una revista de Acceso Abierto; lo que significa que es de libre acceso en su integridad inmediatamente después de la publicación de cada número. Se permite su lectura, la búsqueda, descarga, distribución y reutilización en cualquier tipo de soporte sólo para fines no comerciales y según lo previsto por la ley; sin la previa autorización de la Editorial (Universidad de Deusto) o la persona autora, siempre que la obra original sea debidamente citada (número, año, páginas y DOI si procede) y cualquier cambio en el original esté claramente indicado. Cualquier otro uso de su contenido en cualquier medio o formato, ahora conocido o desarrollado en el futuro, requiere el permiso previo por escrito de la persona titular de los derechos de autoría. 